\title{
Investigator Official Credentials
}

National Cancer Institute

\section{Source}

National Cancer Institute. Investigator Official Credentials. NCI Thesaurus. Code C70949.

A textual description of the investig ator's credentials including, but not limited to the degree(s), board certification(s), license(s), diploma, and other official and/or legal documents indicating that the person has specific knowledge, skills, or abilities in the view of a certifying body. It may also include granted permission(s) to perform a certain activity or hold possession of a specified thing. 